\title{
Cuerpos dolientes: sobre la reparación en mujeres indígenas víctimas de violencia sexual en el Conflicto Armado Colombiano ${ }^{1}$
}

| Aching bodies: The redress in indigenous women victims of sexual violence in the Colombian's armed conflict

Corpos doloridos: reparação de mulheres indígenas vítimas de violência sexual no conflito armado colombiano
Stefannia Parrado Morales ${ }^{2}$

s.parrado2681@uniandes.edu.co

Universidad de los Andes

Bogotá - Colombia

Artículo recibido: 30/04/2014

Artículo aprobado: 01/07/2014

Para citar este artículo: Parrado, S. (2014). Cuerpos Dolientes: sobre la reparación en mujeres indígenas víctimas de violencia sexual en el conflicto armado colombiano.

Ciudad Paz-Ando, 7(1), 24-47

DOI: http://dx.doi.org/10.14483/udistrital.jour. cpaz.2014.1.a02
Este artículo es resultado de una investigación realizada desde el año 2013 como proyecto de grado para la carrera de Ciencia Política de la universidad de los Andes.

2 Politóloga de la Universidad de los Andes. Actualmente es estudiante de Antropología con opción en Economía de la misma universidad.

\section{Resumen:}

El artículo problematiza en el marco del proceso transicional colombiano, la reparación a las mujeres indígenas víctimas de violencia sexual desde dos enfoques. Por un lado, se argumenta la importancia de pensar la justicia transicional desde una economía política que tenga en cuenta las posibilidades reales del Estado colombiano de reparar integralmente a este grupo de víctimas. Y por otro, propone que entender esta economía política requiere de una pregunta por la forma en que la violencia sexual ha afectado la experiencia corporal de las mujeres.

Palabras clave: violencia sexual, cuerpo, construcción de paz, conflicto armado colombiano, mujeres indígenas, reparación integral. 


\begin{abstract}
:
In the context of the Colombian transitional process, this paper discusses, from two perspectives, the redress of indigenous women who have been victims of sexual violence. First of all, this article argues the importance of considering transitional justice from a political economy point of view, which takes into account the real possibilities the Colombian State has in order to do integral reparation to this group of victims. On the other hand, it suggests that understanding this political economy requires a questioning on the way sexual violence has affected women's bodily experience.
\end{abstract}

Keywords: sexual violence, body, peace building, Colombian armed conflict, indigenous women, Integral reparation of victims.

\section{Introducción}

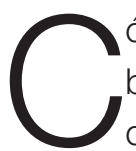
ómo reparar a las víctimas en Colombia es una pregunta tanto complicada como polémica. Ella envuelve, entre otras cosas, la relación entre el desarrollo económico del país y la aplicabilidad, legitimidad y veracidad de los procedimientos pensados en el marco de la justicia transicional. Este artículo parte de la necesidad de pensar esta relación para discutir sobre la reparación integral a las mujeres indígenas víctimas de violencia sexual, pues si bien la aplicabilidad de las herramientas propias de los procesos transicionales es una tarea del Estado nacional, la capacidad real que tiene el Estado para llevarlas a cabo depende no sólo de la disposición política de hacerlo, sino también de su desempeño

\section{Resumo:}

No âmbito do processo de transição na Colômbia, o texto discute a reparação às mulheres indígenas vítimas da violência sexual a partir de duas abordagens. Num primeiro momento, argumenta a importância de pensar a justiça de transição desde uma economia política que leve em conta as reais possibilidades do Estado colombiano para fazer uma reparação integral a esse grupo de vítimas. Por outro lado, sugere que o entendimento dessa economia política requer um questionamento sobre a forma como a violência sexual tem afetado a experiência corporal das mulheres.

Palavras-Chave: violência sexual, corpo, construção da paz, conflito armado colombiano, mulheres indígenas, reparação integral.

institucional, de su capacidad financiera para costear los gastos de capital humano capacitado para el ejercicio que supone reparar, entre otras. El problema de la capacidad financiera del Estado se agudiza en contextos marcados por altas tasas de pobreza, desigualdad social, fragmentación del Estado nación, presencia de corrupción en las instituciones, baja cobertura de servicios básicos, no acceso a derechos fundamentales y otros problemas que generan un escenario de competencia de recursos entre inversión social y agendas de reparación. La pregunta por una economía política de la justicia transicional entonces se hace necesaria si se quiere revisar las posibilidades reales de los estados de iniciar un proceso de transición. 


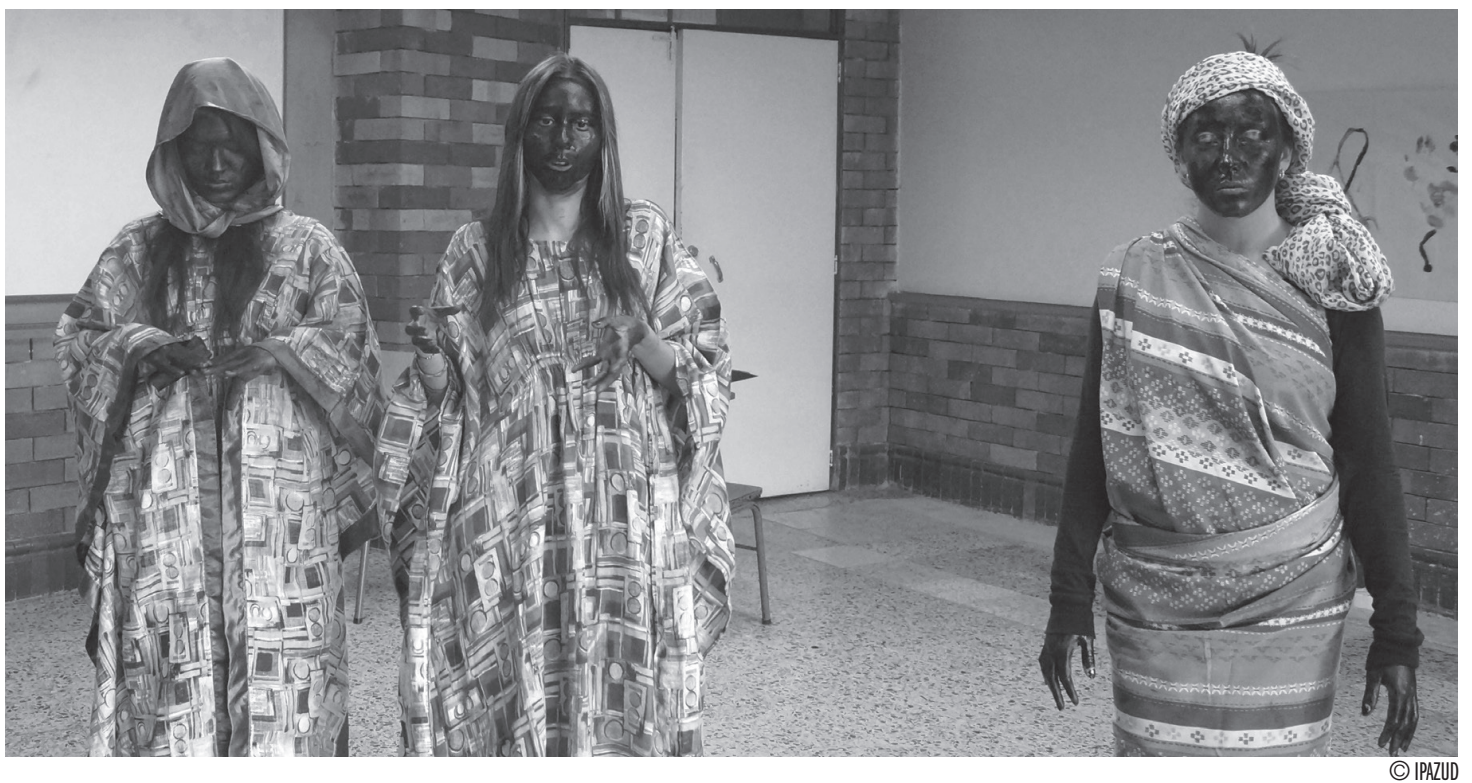

Cuando un Estado se hace responsable de iniciar este proceso, su éxito dependerá de qué tan acordes son la medidas implementadas con los contextos locales. En tal caso, se necesita de algo más que recetas generales sacadas de la experiencia internacional para ajustar las medidas de reparación con las necesidades concretas de las víctimas. Pero saber qué quieren las víctimas sigue siendo un problema mayor, en parte porque todavía hay un desconocimiento considerable de los efectos de la violencia en la vida de las personas. El caso de la violencia sexual resulta bajo este esquema dramático. Un primer problema que surge es por el grado de impunidad que exhibe el delito ${ }^{3}$, y los diversos obstáculos que presentan las mujeres para denunciar el mismo, lo cual genera una imposibilidad de tener datos exactos de la regularidad y el número de casos cometidos en el marco del conflicto armado colombiano, y con ello, la caracterización de los efectos producidos en las víctimas.

Pese a estas dificultades de cuantificar el fenómeno de la violencia sexual, se estima que
3 Según Amnistía Internacional, para el 2004, ésta correspondía al $98 \%$ cerca de 500.000 mujeres han sido víctimas de este tipo de violencia en el conflicto armado colombiano (Oxfam Internacional, 2010), muchas de las cuales son mujeres indígenas (ONIC, 2012) y excombatientes (Londoño \& Nieto, 2006). Además, su prevalencia para el periodo 2001-2009, con base en 407 municipios con presencia de Fuerza Pública, guerrilla, paramilitares $u$ otros actores armados en Colombia, se estimó en $17.58 \%$, lo cual significa que durante estos nueve años, 489.687 mujeres fueron víctimas directas de violencia sexual. Es decir que un promedio de seis mujeres, cada hora, han sido víctimas directas de este tipo de violencia en municipios con presencia de actores armados. El 82,15\% de las 489.678 mujeres víctimas de algún tipo de violencia sexual, es decir, 402.264 mujeres, no denunciaron los hechos que sufrieron, y el $73,93 \%$ de las mujeres considera que la presencia de los grupos armados en dichos municipios constituye un obstáculo a la denuncia de los actos de violencia sexual (Amnistía Internacional, 2004, 2011).

Aunque no hay una definición única de violencia sexual, ésta puede entenderse, 
según la Organización Mundial de la Salud, como aquella que abarca el sexo bajo coacción de cualquier tipo incluyendo el uso de la fuerza física, la agresión a órganos sexuales, el acoso incluyendo la humillación sexual, el matrimonio forzado, la prostitución forzada y comercialización de mujeres, el aborto forzado, la anticoncepción forzada, la mutilación genital y las inspecciones forzosas para comprobar la virginidad. Por su parte, el código penal colombiano la identifica con delitos contra la libertad, integridad y formación sexuales, sancionando todo acceso carnal violento o abusivo. Lo que importa para este artículo, no obstante, no es la definición de la violencia sexual, sino las interpretaciones y significados que las víctimas le atribuyen a la violación. Identidades que atraviesan a la víctima moldean la forma en que ésta recibe el impacto de la violación y el modo en que comprende e interpreta el hecho violento. Estos significados, como se explicará, son un insumo importante para entender cómo deben llevarse a cabo las medidas de reparación y, si se quiere, poder formularlas. Pero también dan cuenta de medidas que no provienen del Estado y que tienen un impacto considerable en la rehabilitación de la cotidianidad (Ortega, 2008), entendiendo que la violencia social trabaja sobre el tejido comunal, lo descompone; pero los individuos resisten y reconstruyen sus relaciones cotidianas y sobrellevan la huella de la violencia de un modo que no siempre aparece perceptible para quien proviene de afuera, sea éste científico social, funcionario, político, etc.

En este sentido, se propone entender cómo la violencia afectó la experiencia corporal de las mujeres indígenas para precisar la pertinencia de las medidas de reparación en el marco de una economía política particular y su potencial para tramitar las secuelas dejadas por el hecho victimizante. Se estudia para ello la relación entre las políticas públicas estatales implementadas y su aplicación en contextos locales, junto con las demandas de las mujeres por la salida de mega proyectos económicos y la desmilitarización de sus territorios como única posibilidad para resarcir los daños en sus cuerpos, sus vidas y su comunidad. Para desarrollar esto se recopilan testimonios y entrevistas de mujeres indígenas víctimas de violencia sexual, y es a través de ellas que se demuestra la tensión presente entre el proyecto económico del gobierno y su disposición a reparar a las víctimas del conflicto. Finalmente, se propone pensar la reparación de estas mujeres como un proceso de continuo diálogo entre las iniciativas estatales con las iniciativas de reparación "desde abajo", o de las comunidades y organizaciones de mujeres.

\section{Pensar la justicia transicional desde la Economía Política}

El Estado colombiano, tras la puesta en marcha de la Ley 1448 de 2011, definió la reparación a las víctimas como una reparación integral. Para el caso de la violencia sexual, ésta debía incluir, además de una indemnización económica, todas las medidas necesarias para garantizar la salud física y emocional de la persona agredida. Siguiendo la lectura que realiza Rodrigo Uprimny \& Saffon (2009, 2007) en lo que respecta a la justicia transicional, el principio de la reparación integral trae paradojas que se enlistan en las limitaciones de este tipo especial de justicia, y que si no se hacen manifiestas, pueden limitar el potencial reparador de la misma. Así pues, que el enfoque de las medidas de reparación adoptadas desde la ley 975 de 2005 haya sido puramente restitutivo dificulta lo que debería ser 
una reparación adecuada y efectiva. Tal opinión de los autores sugiere aquí una primera pregunta, y es si a pesar de los intentos de la ley de víctimas y restitución de tierras (Ley 1448 de 2011) del Gobierno de Juan Manuel Santos, por darle un enfoque transformador a la reparación integral, aún en la práctica, ésta continúa teniendo un enfoque restitutivo. La respuesta afirmativa a tal cuestionamiento bien podría indicar una reparación inadecuada. Aunque no es el propósito de esta parte responder la pregunta, desde la experiencia de las mujeres víctimas de violencia sexual, sí hay indicios para pensar que el enfoque transformador, aunque se adoptó en el discurso, está lejos de llevarse a la práctica. Al respeto, Rosa ${ }^{4}$, víctima de violencia sexual, afirma:

Me parece a mí que para que yo sea reparada integralmente, debería pasar algo que es muy difícil la verdad, es decir que yo sea una mujer digna nuevamente, que cuando salga a la calle no me miren por mi pobreza, y mucho menos me miren mi cuerpo. Que tenga con que alimentar a mis hijos, que me pueda dedicar a ellos y no solo a trabajar, ¿sí? Es que antes por lo menos yo estaba más atenta de ellos, eso era en mi casita, pero cuando llegué a la ciudad, eso el trabajo acá lo esclaviza a uno mucho. Y además, ¿el Estado qué le ofrece a uno? Devolverme a mi tierra, y eso estaría bueno, pero ¿A qué llego allá? A esperar que otro militar llegue y me coja por ahí a una de mis niñas, no, eso no más. (Comunicación personal, 24 de marzo de 2013)

Para examinar mejor este punto es preciso aclarar ciertas cuestiones teóricas. Lo primero es precisar qué entendemos aquí con un

4 Cambia el nombre por petición de la entrevistada. Ella ahora tiene 48 años, es madre de dos niñas y un niño, la mayor tiene 15 años. enfoque restitutivo frente a un enfoque transformador. El primero de ellos hace referencia a los esfuerzos administrativos para borrar los efectos del crimen y deshacer el daño ocasionado con el propósito de restablecer a la víctima en la situación en que se encontraba antes de que el crimen ocurriera (Uprimny, 2009). Este mandato, según el autor, trae cierto tipo de perplejidades, sobre todo cuando el país en donde se ejecuta este enfoque es una sociedad que no está "bien ordenada" en términos rawlsianos ${ }^{5}$ (Uprimny \& Saffon, 2009). En este caso, el enfoque restitutivo resulta problemático en sociedades "bien desordenadas", pues si antes del crimen la víctima era una persona pobre en una sociedad muy desigual, el propósito de restitución sería un atentado a los derechos humanos, y además sería un principio muy débil de justicia porque implicaría retornar a la persona a una situación previa de privaciones materiales y discriminación 6 .

Esto nos lleva a pensar las reparaciones desde una perspectiva correctiva y distributiva, porque implica reconocerlas no sólo como un mecanismo de justicia transicional sino también de justicia correctiva, al intentar esencialmente reparar de manera proporcional un daño sufrido; y de justicia distributiva, puesto que se trata de repensar la distribución justa de los bienes y las cargas en esas sociedades en transición de la guerra a la paz o de la dictadura a la democracia (Uprimny \& Saffon 2009). Ello permitiría, en principio, atender lo que Uprimny ha desarrollado en una literatu-

5 Para Mayor claridad sobre lo que es una sociedad "bien ordenada" véase Rawls, J. (1995). En este libro, el autor expone que una sociedad bien ordenada es aquella orientada por principios básicos de justicia. Es una sociedad donde los bienes están distribuidos de forma equitativa, de modo que "la lotería Natural" (los bienes y talentos con los que se nace), no interfieren en la distribución de la riqueza ni en la posición social que se tenga.

6 Este aspecto también ha sido trabajado por Kalmanovitz (2010) y De Greiff (2006a) 
ra extensa como reparaciones transformadoras $^{7}$, cuyo objetivo principal es transformar las relaciones de subordinación y exclusión social que se encuentran en el origen del conflicto que busca ser superado y que en todo caso aparecen inicuas desde una perspectiva de justicia distributiva (Uprimny \& Saffon 2009), enfoque que para el caso colombiano parece pertinente dada la situación excluyente y desigual en la que están las víctimas antes del trauma causado en la guerra (Ibáñez \& Moya, 2010). Por lo mismo, Uprimny y trabajos que abordan el carácter transformador desde una mirada de género ${ }^{8}$, determinan que este enfoque es capaz de asegurar al menos:

- La participación activa de la víctima en todas las etapas y procedimientos.

- La no discriminación como un principio orientador y como una finalidad del proceso.

- Que la realidad específica de las víctimas se tome en consideración en todo procedimiento y en particular en la definición de las medidas de reparación.

- La búsqueda del empoderamiento de la víctima.

- Que el proceso de reparación incluya medidas específicas encaminadas a superar o por lo menos mitigar las barreras que enfrentan algunas víctimas para acceder efectivamente a las reparaciones.

- La modificación de las condiciones de exclusión en que vivía la víctima y que permitieron o facilitaron su victimización.

Ahora bien, ya que bajo este enfoque se trata de repensar la distribución justa de los bienes y las cargas de la sociedad transicional, resulta un enfoque que mira hacia al futuro preocu-

7 Véase Uprimny (2009), Uprimny \& Saffon (2009) y Uprimny \& Guzmán (2010).

8 Véase: Unifem (2009) y Rincón (2010). pándose por el pasado. Un pasado que, para las mujeres indígenas, pasa por una reflexión de la exclusión de la mujer y el indígena en la sociedad, y de la importancia de vincular este hecho en las memorias colectivas que se constituyen luego de la victimización. De ahí que, tanto para organizaciones de víctimas como académicas, que desde un enfoque de género han analizado el conflicto armado y la reparación, el enfoque transformador es el único que puede garantizar que a la mujer no se le vulnere sus derechos.

Debe entenderse que la violación sexual en un contexto de conflicto armado se enmarca en un ámbito de poder y control violento estructurado por las ideas del privilegio masculino, combinadas con las inequidades étnicas, generacionales y de clase entre las mujeres. (Wills, 2011, p.37)

Y así:

No es lo mismo cuando a una mujer la violan sexualmente que el dolor sentido cuando un hombre es asesinado, desaparecido o desplazado. En su momento el impacto que se sufre es doble para la mujer. Porque ese hombre tiene una mujer y unos hijos. Entonces la mujer es la que recibe el peso del hombre desaparecido, ella queda viuda, tiene que velar por sus hijos, queda madre y padre a la vez, pero es que también la mujer desplazada, que ya fue violada, tiene que irse a un territorio que no es el suyo y para cuidar a sus hijos ¿cómo lo hace en un lugar donde no conoce nada?, no sabe. Es diferente, un hombre puede ser desplazado pero puede que este se desplace solo, en cambio la mujer no puede dejar a sus hijos tirados, ella no puede decir yo me voy porque yo soy la que está en problemas, no, ella sale con sus hijos, ella siempre está pensando en su familia y su comunidad, en sus primos en sus tíos. El hom- 
bre puede defenderse solo pero la mujer sufre más riesgo, porque la ven débil y se pueden aprovechar.(A.Guzmán ${ }^{9}$,comunicaciónpersonal, 10 de abril de 2013)

La Ley 1448 de 2011, en su artículo 13, establece que la reparación integral debe estar pensada en términos cuidadosos con el género, la edad, la orientación sexual y la situación de discapacidad, así como debe atender las condiciones particulares y diferenciadas existentes en cada región. De ahí que en el Subcomité que trabaja por el enfoque diferencial de la reparación se cuente con la participación de la Consejería Presidencial Para la Equidad de la Mujer, con el Programa Presidencial Para el Desarrollo Integral de la Población Afrocolombiana, Palenquera y Raizal y de los Pueblos Indígenas. No obstante, la victimización por violencia sexual es reconocida recientemente, en parte, por la presión de las organizaciones defensoras de los derechos de las mujeres y de las sobrevivientes de la guerra, que han dado a conocer las formas particulares en que se ha victimizado la mujer en el conflicto armado y de la importancia, después de Justicia y Paz, de introducir un enfoque de género en la manera en que se estaba abordando los crímenes en el conflicto (Unifem, 2009; Wills, 2011).

Así, se ha logrado mostrar en los últimos años el carácter diferencial y la manera desproporcionada en que han sido víctimas hombres y mujeres, pues es a ellas a quienes su condición de mujeres las ha llevado a ser vulnerables a múltiples violaciones a los derechos humanos; es decir, son mujeres que de forma paralela son víctimas por la pérdida

9 Consejería Mujer Familia y Generación en la ONIC -Organización Nacional Indígena de Colombia-.Esta consejería, entre muchas otras labores, denuncia y documenta los diferentes casos de violencia sexual en mujeres indígenas. de seres queridos, por ser desplazadas y por ser violadas sexualmente ${ }^{10}$ (Corte Constitucional, 2008). Esto ha impedido, entre otras cosas, la cuantificación de las víctimas de violencia sexual, porque en su mayoría las mujeres se tienden a identificar como víctimas de otras prácticas, como desplazamiento, por ejemplo. Además de la falta de garantías para la denuncia y la negativa de muchas de ellas para contar lo sucedido, como lo definió la corte constitucional, "existe un triple proceso de invisibilidad oficial y extraoficial, silencio por parte de las víctimas, e impunidad de los perpetradores" (Corte Constitucional, 2008).

$\mathrm{Al}$ respecto, se han identificado algunas causas para la violencia sexual contra las mujeres en estos contextos: por un lado, la intención de humillar a la comunidad de la cual es parte la mujer, y a los hombres que no 'cumplieron' con su rol de protección ${ }^{11}$. Por otro lado, se identifica la conexión entre la militarización de un Estado y la violencia contra la mujer $^{12}$. Es importante resaltar que la violencia sexual en estos contextos tiene diferentes connotaciones, que van desde el cuerpo de la mujer como botín de guerra (Betancur, 2011; Oxfam Internacional, 2009; Amnistía Internacional, 2004) hasta la intención de sembrar terror y embarazar a las mujeres de una determinada comunidad (Oxfam Internacional, 2009; Memoria Histórica, 2011). También se reconoce que las mujeres que con más frecuencia resultan víctimas de estas conductas son aquellas que tienen un papel de liderazgo (muchas de las mujeres que fueron defensoras de derechos humanos, recibieron como castigo la violencia sexual) o que tienen una

10 El trabajo de Rettberg (2008) por ejemplo, reporta que 71,5\% de las víctimas consultadas en ese estudio declaran sólo una forma de victimización, $19,5 \%$ dos formas de victimización y $5,4 \%$ tres formas de victimización.

11 Véase por ejemplo el caso de la masacre de Bahía Portete documentado por Memoria Histórica (2010).

12 Sobre este tema véase Chinkin (1994). 
relación afectiva, bien sea con miembros de la fuerza pública o con miembros de grupos armados ilegales.

Ahora bien, cuando se hablaba de reparación trasformadora se mostró cómo bajo este enfoque las reparaciones juegan un papel fundamental en el progreso democrático y justo de la sociedad, de modo que funcionan como herramientas para la resolución del conflicto y la transición hacia la paz, a la vez que ayudan a superar situaciones de exclusión y desigualdad que resultan contrarias a principios básicos de justicia distributiva. Lo que quiere, en general, es transformar las estructuras económico-políticas que facilitaron la victimización. En este orden de ideas, resultaría también sencillo afirmar que la reparación, al jugar un papel redistributivo en la sociedad, conjuga mecanismos que propenden a garantizar, por ejemplo, educación, salud y nutrición, capacitación laboral, seguridad social y vivienda; además de acceso a servicios básicos como el agua y saneamiento básico, recreación y cultura, apoyo a empresas familiares y distribución de tierras, etc. Esto sonaría perfecto si no fuera porque Colombia, gracias a la carta constitucional de 1991 que le reconoce como un Estado social de Derecho, le otorga al Estado ciertas obligaciones, entre ellas garantizar los Derechos Sociales Económicos y Culturales (DESC). De modo que, parecería que lo que se planteaba como un mecanismo de reparación a las víctimas son responsabilidades adquiridas por el Estado gracias a la carta constitucional.

El temor de no reconocer tal diferencia radica, en principio, en que el Estado como medida de reparación acabe dando lo que de por sí es ya su obligación; y segundo, en que ello podría derivar en conflictos entre la población vulnerable que demanda la atención del Estado por medio de planes sociales, y las víc- timas que lo reciben sólo por su condición de victimización, reconociendo, claro está, que el Estado Colombiano no ha garantizado para toda su población estos derechos básicos a los que como ciudadanos tenemos derecho. Es necesario, pues, aclarar las diferencias que establece un programa de atención a víctimas, uno de inversión social que busque entre otras cosas el desarrollo económico del país, y programas de asistencia humanitaria, con el fin de preguntarse ¿Cómo una institución que históricamente ha sido incapaz de garantizar que sus habitantes tengan derecho a la satisfacción de sus necesidades básicas, puede en poco tiempo responder a las demandas de inversión social y reparación? Esta pregunta es importante porque incurre en si darle esta capacidad transformadora a la reparación no resultaría una propuesta ambiciosa destinada a fracasar ${ }^{13}$.

A grandes rasgos, la reparación de las víctimas de crímenes atroces, la prestación de servicios sociales a todos los ciudadanos y la atención humanitaria a víctimas de desastres son deberes autónomos en cabeza del Estado, que tienen un origen, unas fuentes jurídicas y una razón de ser diferentes (Uprimny \& Saffon 2007). De igual manera, están orientadas a poblaciones diferentes ${ }^{14}$. La siguiente tabla sintetiza las diferencias:

13 Para una visión escéptica de la posibilidad de que las reparaciones cumplan una función tan ambiciosa como la transformación véase Mani (2006).

14 La ley 1448 no desconoce esta diferencia (ver parágrafo 1 y 2 del artículo 25). Sobre Atención Humanitaria para las víctimas ver Artículos 62, 63, 64 y 65. No obstante, los recursos prestados por asistencia humanitaria y por inversión social hacen parte de los montos reconocidos por reparación. Ello trae problemas en términos de discursos, ya que el Estado en las cifras presentadas por motivo de reparación incluye los gastos que hacen parte de programas de desarrollo e inversión social. Además, esto provoca que las medidas tomadas con motivo de reparación no sean explícitamente para víctimas, lo que puede generar peleas entre víctimas y población vulnerable. Tampoco el Estado cumple con tomar a las víctimas como ciudadanos con igualdad de derechos como lo propone De Greiff (2006b), es decir, no por ciudadanas reciben las ayudas para sacarlas de su vulnerabilidad y marginalidad, sino por ser víctimas. 
Tabla 1. Distinciones entre reparaciones, política social y asistencia humanitaria

\begin{tabular}{|c|c|c|c|c|c|}
\hline & Origen fáctico & $\begin{array}{c}\text { Bases } \\
\text { normativas }\end{array}$ & Propósito & Beneficiarios & Mirada temporal \\
\hline $\begin{array}{l}\text { Asistencia } \\
\text { humanitaria }\end{array}$ & $\begin{array}{l}\text { Catástrofe o } \\
\text { emergencia }\end{array}$ & $\begin{array}{l}\text { Principio de } \\
\text { solidaridad y } \\
\text { deberes de } \\
\text { protección del } \\
\text { Estado }\end{array}$ & $\begin{array}{l}\text { Mitigar riesgo } \\
\text { y reducir } \\
\text { vulnerabilidades }\end{array}$ & $\begin{array}{l}\text { Personas en } \\
\text { crisis }\end{array}$ & $\begin{array}{l}\text { Ahora y hoy, pues } \\
\text { la atención es } \\
\text { urgente }\end{array}$ \\
\hline Política social & $\begin{array}{l}\text { Situaciones } \\
\text { de pobreza, } \\
\text { exclusión y } \\
\text { desigualdad }\end{array}$ & $\begin{array}{l}\text { Justicia } \\
\text { distributiva y } \\
\text { deberes estatales } \\
\text { frente a los DESC }\end{array}$ & $\begin{array}{l}\text { Satisfacer } \\
\text { necesidades } \\
\text { materiales } \\
\text { básicas }\end{array}$ & Pobres & $\begin{array}{l}\text { Hoy, para el } \\
\text { contenido esencial } \\
\text { de los DESC y la } \\
\text { identificación de } \\
\text { los beneficiarios. } \\
\text { En el futuro, para } \\
\text { la realización } \\
\text { progresiva de los } \\
\text { DESC }\end{array}$ \\
\hline Reparaciones & $\begin{array}{l}\text { Ofensas y graves } \\
\text { violaciones } \\
\text { de derechos } \\
\text { humanos y del } \\
\text { DIH }\end{array}$ & $\begin{array}{l}\text { Justicia correctiva } \\
\text { y deber de } \\
\text { reparar }\end{array}$ & $\begin{array}{l}\text { Borrar en lo } \\
\text { posible las } \\
\text { consecuencias } \\
\text { de la ofensa }\end{array}$ & Víctimas & $\begin{array}{l}\text { Ayer, pues se } \\
\text { trata de corregir } \\
\text { los efectos de un } \\
\text { hecho pasado }\end{array}$ \\
\hline
\end{tabular}

(Tomado de Uprimny \& Saffon, 2009, p.48)

La confusión de estas tres agendas puede conducir a conclusiones que entorpecerían el carácter reparador que se busca en la ley de Víctimas. Podría, o terminar por aceptarse la conclusión en la cual el programa de reparación a las víctimas se interpreta como una ley mesiánica que, en poco tiempo, puede apalancar desarrollo económico, democratización de las instituciones, redistribución de la riqueza con miras a una sociedad "bien ordenada" y, en general, una situación duradera de paz; o en la confusión y no delimitación de las diferentes agendas, que las acciones que hace el Estado se centren en aspectos que mejoren la calidad de vida de la víctima, pero no se responsabilice de otras tareas que están relacionadas con el reconocimiento público de la culpa, el esclarecimiento de la verdad, las garantías de no repetición en términos de conformar una memoria "formativa"15, reparación con contenido simbólico (Uprimny y Saffon 2009), entre otras que atañen específicamente a deudas pendientes con las víctimas y no con las personas pobres y vulnerables o con las personas en crisis. De ahí que no pueda tomarse un programa de reparación como un programa de desarrollo, sin desconocer con ello que es saludable que las reparaciones puedan desempeñar un papel en propiciar el Estado de Derecho en situaciones transicionales y de posconflicto, primero porque las reparaciones pueden ofrecer reconocimiento a las víctimas de sus derechos. Segundo, porque las reparaciones pueden aumentar el nivel de confianza cívica, en particular, el

15 Es decir, que es una memoria que contando y narrando el pasado da lecciones para un futuro (Orozco, 2009). 
de la confianza en nuevas instituciones (De Greiff, 2006a). Y tercero, porque el programa de reparación puede ser una oportunidad para la superación de situaciones de exclusión e inequidad (Uprimny \& Saffon, 2009).

Lo importante es reconocer que dada una situación de reparaciones masivas, con Estados frágiles, economías débiles o de sociedades desordenadas, la preferencia de los gobiernos será movilizar recursos hacia programas de asistencia social que a aquellos contemplados para la reparación a las víctimas del conflicto (Segovia, 2006); o como lo plantea Kalmanovitz (2010), cuanto más destructiva sea una guerra, menos fuerza tendrán los derechos a la reparación y más énfasis deberá darse a políticas de reconstrucción orientadas a garantizar derechos básicos en toda la población. De este modo, si en estos contextos se llegan a acoplar planes de reparación, estos serán procesos lentos, dadas las dificultades producto de los límites de recursos e institucio$n^{16}{ }^{16}$. Si se reconoce, entonces, que Colombia es uno de estos casos, la pregunta por el desarrollo económico salta a la vista. Es notable que una urgencia para el país sea desarrollar su economía y generar los recursos suficientes para afrontar los problemas socioeconómicos más importantes como la pobreza, la desigualdad, la cobertura de servicios básicos etc.

16 En De Greiff (2006a) y De Greiff (2006b), el autor muestra que cuando un país con limitaciones prácticas y presupuestales decide llevar a cabo un programa de reparación, este no puede ser ambicioso pues estará diseñado al fracaso. Reconoce que un bajo desarrollo económico y un universo amplio de beneficiarios potenciales impone grandes restricciones a la capacidad de un gobierno para implementar un plan de reparaciones. Como sucedió en Guatemala, El salvador y Haití que no desarrollaron ningún plan de reparación, mientras si lo hizo Chile, Argentina y Brasil. No obstante, no siempre no se dan procesos de reparación por limitaciones económicas. Así, Segovia (2006) advierte que son la ausencia de coaliciones amplias y fuertes en favor de las reparaciones lo que repercute en la formación de los programas. Un ejemplo de ello es Sudáfrica, que aun cuando tenía los recursos para reparar con mejores resultados que los obtenidos, decidió un programa modesto.

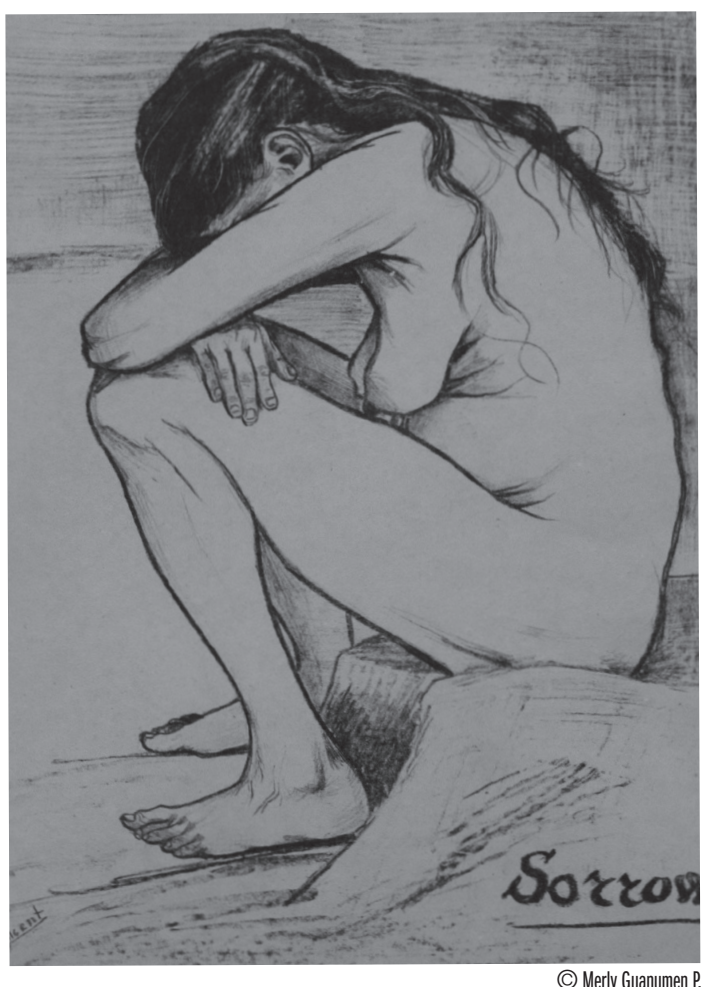

(C) Merly Guanumen P.

Ahora bien, así como el Gobierno de Juan Manuel Santos inició el proceso de paz a través de las negociaciones en La Habana con el grupo armado de las FARC, y estableció su propuesta para reparar a las víctimas (Ley 1448), también muestra un proyecto económico concreto $^{17}$, que como se demostrará más adelante aparece como un impedimento para lograr la reparación a las mujeres indígenas víctimas de violencia sexual, en concreto por la locomotora Minera. Por eso, el caso específico de las mujeres indígenas, como se argumenta en este escrito, amerita pensarlo en clave de una economía política de la justicia transicional, que detalle las necesidades del Estado de priorizar entre agendas de reparación, desarrollo económico, desarrollo

17 El gobierno del Presidente electo Juan Manuel Santos en su Plan de Desarrollo para el periodo 2010-2014, planteó cinco 'locomotoras' como clave del desarrollo del país: Infraestructura, Minería, Vivienda, Agro e Innovación. 
social en clave de respetar los DESC, etc. Sin embargo, esto también supone entender la importancia que tiene para la mujer indígena su territorio, y cómo la violencia sexual, además de secuelas físicas en sus cuerpos, deja una comunidad afectada y un territorio devastado. En efecto, esta segunda parte del escrito centra su mirada en la manera en que la violencia sexual afectó la experiencia corporal de la mujer indígena, así como hace una aproximación de la manera en que ésta entiende su cuerpo. Aunque antes, se aclara por qué empezar con una mirada del cuerpo para entender los efectos de la violencia sexual.

\section{La violencia se marca en los cuerpos: ¿por qué importa la experiencia corporal para una economía política de la justicia transicional en el caso de las mujeres indígenas?}

Los cuerpos de las mujeres han sido territorios de disputa en el conflicto armado colombiano, han sido "botín de guerra" (Salcedo, 2007; Onic, 2012), en el cual la violencia sexual se convirtió en la estrategia de los actores del conflicto (fuerzas armadas, paramilitares, guerrillas) (Oxfam Internacional, 2009), para demostrar el control de un territorio o para violentar espacios domésticos y comunitarios (Memoria Histórica, 2012). La destrucción del cuerpo de las mujeres como actos simbólicos para controlar la guerra, implica pensar en unos mensajes que se tranzan a través del cuerpo femenino y que les otorgan cierta posición al violador y a su víctima. No es pues gratuita la aparente desmoralización que recae en la mujer que ha sido violada y que la conduce a sentimientos como la vergüenza de su propio cuerpo e incluso su misma negación. La violación sexual, entonces, genera una transformación de la disposición corporal de la mujer a la vez que transforma su estética corporal. Cambios que alteran la experiencia vital de las mujeres y afecta su capacidad de duelo y de tramitar el dolor dejado por el hecho victimizante. Indagar así por cómo la violencia afecta la corporalidad de la víctima importa si se quiere pensar la manera de reparar a estas mujeres acorde a las formas particulares en que se ejerció la violencia contra ellas, ya que aunque hay desafíos a nivel institucional para repararlas ${ }^{18}$, las mujeres víctimas de este delito siguen sus vidas, resisten a la descalificación moral que les genera ser violadas sexualmente en una sociedad patriarcal y además vuelven su testimonio una herramienta para luchar por el conocimiento de la verdad sobre este crimen, su judicialización y la reparación ${ }^{19}$.

Tres razones explican entonces la preocupación por el cuerpo en este delito: a) El cuerpo es el lugar donde se ejerce e inscribe la violencia, en especial cuando es una violencia sexual. Si a la víctima se le violentó su cuerpo, ¿cómo ella entiende esa violencia? ¿Cómo logra vivir con un cuerpo marcado por la violencia? b) El cuerpo es el lugar de exposición con la comunidad, es lo que se ve, lo que denota significado, entonces, ¿cambia la exposición del cuerpo luego de la violencia ejercida contra él? ¿Cómo esto influye la capacidad de la víctima de tramitar su dolor y hacer duelo, es decir, de recuperar sus recursos, significados y relaciones para que reoriente su vida y restaure su integridad personal y social ${ }^{20}$ ? y

\footnotetext{
18 Algunos de los obstáculos que se presentan para reparar integralmente a las víctimas tiene que ver con la poca información que se reporta al respecto y la falta de garantías para su denuncia. Para más información véase: Amnistía Internacional, 2004; CINEP 2012; Mesa de Trabajo Mujer y Conflicto Armado, 2009 y Mesa Nacional de Seguimiento al Auto 092, 2011.

19 Que aunque afecta a hombres, niños, niñas y personas de edad, la mayor parte de las víctimas son mujeres.

20 Preocupación que se ha planteado la perspectiva generativa en la gestión de los conflictos sociales.
} 
c) La violencia afecta la cotidianidad de la víctima, es decir, la manera en que transcurre su día a día, sus relaciones sociales, su manera de estar en el mundo y de asumir una realidad. Una reparación en este sentido debería en principio rehabilitar lo cotidiano (Ortega, 2008) pues sólo así la víctima podrá continuar su proyecto de vida. La cotidianidad se vuelve un problema para la construcción de paz, y una manera de abordar lo cotidiano es desde la experiencia corporal, pues representa lo "más íntimo" y por ello la forma primera de afectar la relación con el mundo. Estas tres ideas serán ampliadas para explicar por qué la pregunta por el cuerpo es relevante para una economía política de la justicia transicional en el caso de las mujeres indígenas.

Ahora bien, preguntarse por el cuerpo de la víctima tiene unas consideraciones éticas que involucran mirar críticamente la manera en que se reconstruyen los hechos para acceder a la verdad, y de ella derivar un ejercicio de memoria capaz de dignificar a las víctimas. La pregunta por cómo la violencia afectó la experiencia corporal de la víctima trae a colación la necesidad de plantearse nuevas formas de sensibilidad ética que tomen en cuenta las modalidades operativas de destrucción sobre el cuerpo de la mujer (Segato, 2009), y con ello una ética que determina nuestra capacidad de respuesta y empatía con el delito. Ello tendrá que ver con una ontología basada en la concepción del ser humano que es siempre en consideración de un otro, lo cual implica pensar en las consecuencias que trae la experiencia de la violencia para quien la sufre, no sólo por sus efectos materiales, sino también por la forma en que reestructura los sentidos y la disposición corporal del sujeto (Butler, 2010).

"Tener en cuenta el cuerpo" a la hora de hablar de las particularidades de la violencia ejercida contra las mujeres y la manera diferenciada en que ellas deben ser reparadas no es suficiente, también es necesario advertir sobre cómo se entiende el cuerpo. La herencia cartesiana que escinde la res cogitans y la res extensa, donde el cuerpo no es más que una "probable conjetura", una "ilusión de mi espíritu" (Horenstein, 2004), debe ser superada para atender a un planteamiento fenomenológico que entienda que el cuerpo no es sólo una realidad observable como objeto, sino que es una dimensión del propio ser. Como lo plantea Merleau-Ponty, el cuerpo es el medio de nuestro ser-hacia-el-mundo, donde el 'ser-en-el-mundo' de Heidegger es ante todo un 'ser-corporal-en-el-mundo', Io que implica una 'pertenencia al mundo', a un hallarse 'implicado' en el mundo a través del cuerpo, el cual además, abre a un sujeto al mundo (Cadavid, 2006).

Esta fenomenología de la experiencia corpórea ayuda a entender por qué cada persona corrobora, mediante su experiencia particular, que le es físicamente imposible escapar de su cuerpo si quiere estar, de una u otra manera, en este mundo (Serres, 2011). Sin embargo, también permite entender por qué una experiencia dolorosa admite la reflexión del cuerpo -de su existencia carnal- de modo que enfrente al ser con su sí mismo (López, 2010). El enfoque fenomenológico permite, en este sentido, darle primacía a la experiencia subjetiva inmediata como base del conocimiento, así como el estudio de los fenómenos desde la perspectiva de los sujetos, teniendo en cuenta su marco referencial; $y$, finalmente, conocer cómo las personas experimentan e interpretan el mundo social que construyen en interacción, y que para el caso estudiado está mediado por experimentar una situación que coloca al cuerpo en los límites del sufrimiento. Lo importante aquí no es la descripción de las 

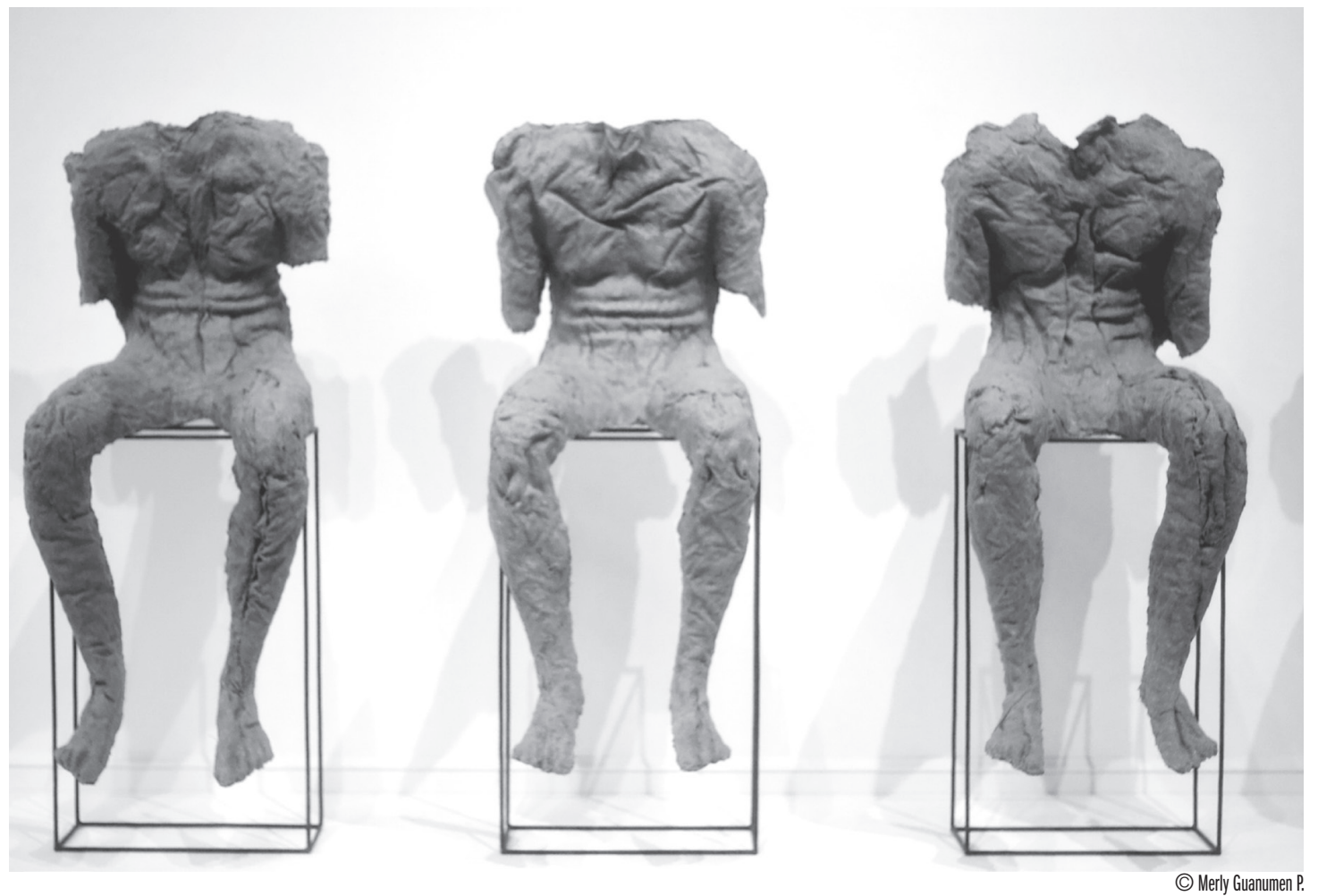

condiciones que afectaron la corporeidad de la mujer; es decir, la narración de los hechos, sino la forma en que los hechos configuraron nuevas subjetividades en la víctima y le dispusieron una serie de arreglos corporales que inciden en la forma en que ella vuelve a enfrentar su vida -su cotidianidad- y cómo la rehabilita (Ortega, 2008).

Esta perspectiva es mucho más cuidadosa con los efectos reales que tuvo la experiencia de victimización sobre las mujeres y permite escapar a los discursos técnico-científicos que definen las secuelas en términos clínicos, apropiándose del sufrimiento de la víctima y despojándola de toda autoridad que ella tenga sobre su dolor y sobre la manera en que ella lo interpreta y administra (Das, 1996 citado en Ortega, 2008). Situación problemática que se agudiza en el caso de las mujeres indígenas en la medida en que las formas de reparación no atienden a las particularidades culturales, y además es un terreno aún desconocido hablar de cómo la mujer indígena entiende su cuerpo. No obstante, fruto de la recolección de testimonios, este trabajo pretende dar una idea de cómo la experiencia corporal de la mujer indígena se vio afectada por la violencia sexual, ello para dar pistas de cómo a través de un estudio de la cotidianidad de las mujeres, vistas a través de sus cuerpos, es posible valorar las medidas de reparación que necesitan en el marco del proceso transicional colombiano.

Para las mujeres indígenas, por ejemplo, la violación sexual además de violentarlas a ellas, agrede fuertemente a la comunidad:

Desde la cosmovisión indígena las mujeres somos sagradas y venimos a cumplir un papel fundamental en el territorio y es la de apaciguar y mantener el equilibrio en las comunidades. Cuando se quebranta eso es muy difícil de explicarlo. Aunque en la comunidad se den 
cuenta que llega un autor externo y comete alguna violación contra la mujer eso no se pone a la luz pública, porque eso significa entrar a explicar muchas cosas que son difícil de explicar. La comunidad entera sufre cuando a sus mujeres las violentan. (D. Tavera, comunicación personal, 23 de abril de 2013)

Así como los efectos de la violación puede exceder el marco interpretativo occidental puramente clínico:

Por ejemplo con un caso que tenemos de una niña Wiwa que ella estaba haciendo todos los pasos para ser Saga, la Saga es como el femenino del mamo, y es la guía espiritual de la comunidad. Ella desde que nace está destinada para ser Saga, ella tiene 9 años y un soldado la violó, entonces ahí termina su proceso, porque no lo puede continuar, y en otros espacios dirán bueno pero es que ella no tuvo la culpa, pero no, es que no se puede simplemente no lo permite la ley de origen. $Y$ eso es una manera de acabar con los pueblos. (D. Tavera, comunicación personal, 23 de abril de 2013)

Ahora bien, así como no todas las víctimas responden de igual forma ante los hechos y acontecimientos que envuelven sus vidas y le otorgan distintos sentidos a sus experiencias de victimización, los usos de la memoria también son diferenciados, y muchas veces dependen de las identidades (étnicas o políticas) que atraviesan a la mujer. Mientras una víctima decide silenciar los hechos ocurridos pretendiendo de esta manera olvidarlos -0 manifestarlos-, para otra se hace necesario tenerlos presentes porque esto le permite reivindicar su condición de víctima, dignificarse como ciudadana portadora de derechos, o simplemente rehacer su proyecto de vida. Así por ejemplo,
No es fácil para la mujer indígena llegar a un espacio y decir a mí me violaron, mi papá, las guerrillas hicieron esto conmigo, no es fácil primero porque la mujer indígena es muy reservada y no da a conocer todo lo que pasa con ella. (A. Guzmán, comunicación personal, 10 de abril 2013)

De modo que muchas silencian lo que pasa, pero también,

Hay compañeras que ahí donde tú estas, tú las ves que salen adelante y tú las ves felices, pero que también fueron víctimas, y a veces cuando hablan con las otras mujeres para darles ánimos se atreven a contar y dicen vea yo también fui violada, a mí me tocó mi papá, yo fui violada por mi padrastro, entonces yo te puedo decir que yo me he recuperado algo, y que haciendo algo yo he podido salir adelante. (A. Guzmán, comunicación personal, 10 de abril 2013)

Tales particularidades -dificultades y retosque expone pensar la violación en las mujeres indígenas y además la reparación que le debe corresponder al Estado promover, también tiene que ver con cómo nos acercamos a una definición del cuerpo para ellas de manera tal que el mismo no se entienda ni se conceptualice desde un marco occidental. Por ejemplo, Tavera explica que:

El cuerpo de la mujer se asemeja a la tierra. En los pueblos indígenas la tierra es la madre, entonces los hombres asocian a las mujeres con la madre tierra. Todo lo que se le haga a la madre tierra pues afecta todo, cierto, entonces hay una cosa muy difícil de explicar en la violación sexual. Las indígenas del pueblo Emberá Dobida, usan solo la paruma, que es como la faldita, y ellas se dejan descubiertas la parte de arriba y se cubren con jagua que es la pintu- 
ra negra, entonces para los pueblos indígenas es normal ver a una mujer indígena así, pero para los que vienen de afuera no, entonces por ejemplo, yo fui hace muchos años y estaban con la paruma, y fui el año pasado y ellas estaban con camisetas, entonces me contaban que los soldados iban y les tocaban los senos y las hacían avergonzar, entonces es la manera como usted mira el cuerpo de la mujer indígena, nada más con mirarla, entonces ellas me contaban: no es que el soldado me avergonzó y avergonzarlo a uno es hacerlo entender que hay partes que no se pueden mostrar cuando eso era normal en la tradición del pueblo. Era natural que la mujer esté así, pero entonces las han avergonzado de su cuerpo expuesto cuando también es normal que el viento, la luna, las estrellas equilibren mi cuerpo, ¿sí? entonces cuando llegan a violentar a la mujer se dejan marcas, aparte de las marcas físicas que pues en una violación quedan ¿no?, les jalan el pelo, se los cortan, cuando para la mujer indígena tener el cabello largo significa fortaleza y una serie de cosas, entonces es una de las formas que afecta a las mujeres cuando alguien llega y las hace avergonzar y eso causa mucho dolor interior, porque ya no puedo estar como estaba antes y esa es una violencia que no se puede reparar porque nunca vamos a poder ser las mismas y eso es muy difícil de explicar. Los mismos hombres de la comunidad ya no ven el cuerpo de la mujer como antes, como su compañera, sino que ya la ve con otros ojos. Y eso es difícil de reparar, remendar más bien, cuando ellas hablan de reparar ellas hablan de remendar, usted sabe que es un remiendo ¿sí? Que lo cosen pero queda la marca ahí. (Comunicación personal, 23 de abril de 2013)

El cuerpo se entiende entonces no como categoría con un significado único, sino en relación a los elementos que afectan la cor- poreidad. Cuando se dice que algo afecta el cuerpo, se habla de las marcas que quedan en el cuerpo físico:

A una mujer en Córdoba que tenía una cabellera abajo de las nalgas, vea esa cabellera era su adoración, iy los paramilitares llegaron y se lo cortaron! Y le dejaron su cabello cortico y no solo eso, la torturaron, le quemaron sus piernas le dejaron cicatrices ¿sí? Y esa mujer a pesar de todo eso no se ha visto débil frente a lo que ha tenido que vivir como mujer indígena. (A. Guzmán, comunicación personal, 10 de abril de 2013)

Pero también en los cambios estéticos del mismo:

Hay un caso que llevamos con los Nukak Maku. Que fueron unos militares que violaron a una niña, entonces ella que andaba con sus vestiditos ya los odia, ya ella lo único que utiliza es pantalón. Si tu estas acostumbrada a tu ropita, $\mathrm{y}$ te da miedo al ponerte vestido porque fulanito de tal me va a tocar, me va a violar, entonces hay miedo, y por eso las indígenas pierden usos y costumbres. (A. Guzmán, comunicación personal, 10 de abril de 2013)

$Y$ en especial en los significados que quedan en el cuerpo de la víctima:

Mire para mí fue difícil después hasta bañarme, porque después de que pasa usted por eso ya parece que su cuerpo no fuera su cuerpo. Usted siente que por sus brazos, por todo está ahí la persona que lo violo a uno. Entonces usted se siente sucia, se siente como que su cuerpo quedo manchado, y es difícil entender que uno sigue siendo la misma, es difícil. (Rosa, comunicación personal, 24 de marzo de 2013) 
El cuerpo, en todo caso, no es solo una estructura fisiológica, sino que es también una estructura culturalmente formada y formable, ante la que no podemos adoptar una actitud neutral. En la concepción de cuerpo se entrelazan aspectos sociales, de género, matices étnicos, e incluso tintes religiosos que configuran la actitud frente a la corporalidad. El cuerpo constituye, por ello, una realidad simbólica por medio de la cual se despliega todo un significado ontológico que se descubre, o más bien se contempla por la comunicación con otro cuerpo simbólico.

Por eso, para Jean - Luc Nancy (2008), el cuerpo puede entenderse como lugar de la exposición, de la exterioridad y de la apertura a los otros, desde su contacto físico, visual y desde su existencia como materialidad. El cuerpo, en tal sentido, guarda relación con la comunidad pues ésta es lo que nos ocurre desde siempre, lo que nos sucede, es el hecho de ser-con-otros en el mundo. Por eso, somos siempre con otros y por eso es que estamos expuestos a ellos desde nuestra exterioridad. Es más, como esta exposición a los otros es lo que nos hace ser, lo que nos caracteriza, la existencia se concibe como existencia, exposición y apertura hacia los otros con los que somos. Ahora bien, en Corpus (2008), Nancy se plantea que la existencia así concebida tiene lugar en el cuerpo. Así, somos 'comunidad de los cuerpos'. Esta exposición a los otros es clave para entender los impactos en el cuerpo de la víctima y las formas en que ella resiste a la imposición de la violencia.

La violencia, cuando es ejercida en el cuerpo de la víctima, rompe los significados que ésta le atribuía a su cuerpo y que se manifiesta también en la exposición de éste a la comunidad. Es así como la víctima de violencia sexual tiene la sensación de "sentirse extraña". Cuando esto pasa, cuando no sabe cómo entenderse porque hay algo que no la deja sentirse bien consigo misma, la víctima difícilmente puede hablar de lo sucedido, en parte, porque es exponerse a un público. Cuando ellas hablan, no sólo lo hacen por las palabras que emiten sino también por sus cuerpos, aquellos que fueron marcados y resignificados por la violencia. Por ello muchas al hablar esconden su cuerpo, "se muestran tímidas" (A. Guzmán, comunicación personal, 10 de abril de 2013), se les hace difícil exponerlo ante hombres. El cuerpo femenino las averguenza porque por él fueron victimizadas. Por ello, lograr transmitir una experiencia del sufrimiento pasa por una resignificación del cuerpo propio, algo que da cuenta de la posibilidad de la víctima de exponer su cuerpo a la comunidad, de exteriorizarlo, de mostrar incluso las cicatrices cuando éstas quedan como efecto de la violación.

Ahora bien, si los cuerpos hablan, la relación de violencia y lenguaje también pasa por el cuerpo. Las mujeres contaron que iniciar un proceso de narración de experiencias personales es difícil, porque entran el llanto, el silencio, la depresión a conjugar el modo en que comunican algo. Ese "no encontrar palabras para expresarme" también es apropiarse de formas de transmitir la experiencia de victimización. Justamente a algunas de las víctimas no les basta decir me causó dolor, sufrimiento, etc., porque las palabras no expresan el significado que para ellas tuvo la violencia. Hay una ruptura de categorías y del sentido de las palabras -rupturas del lenguaje- que hacen necesarias nuevas formas de expresarse. Estas nuevas formas de expresarse muchas veces pasan por expresiones artísticas (performance) que sitúan el cuerpo como objeto contenido de sentido. El cuerpo, además, aparece como testimonio, como la fotografía que queda de la violencia. 
Para Rita Segato (2003) lo particular de la relación de cuerpo-violencia sexual, es que el cuerpo funciona como escenario de transmisión de mensajes entre varones que buscan mostrar su capacidad de controlar un territorio, de ejercer hegemonía en el mismo, y de demandar obediencia a todos los sujetos que allí se encuentran, incluso cuando lo que se tranza es el cuerpo femenino. Así, el cuerpo se controla y se dispone de él, se ejerce soberanía, es decir que el perpetuador pasa a tener el monopolio legítimo -en términos weberianos-, del cuerpo de la víctima. Ésta, entonces, pierde toda autonomía sobre su cuerpo y ya no es suyo, es despojada moral y físicamente de la autoridad de su cuerpo. La violencia sexual, por ello se inscribe en un campo comunicativo de transmisión de significados (Segato, 2003), y es en esta comprensión de la violencia sexual que cabe la pregunta por los significados que emanan en la experiencia de victimización.

Cuando en la violación se le da el mensaje a la víctima de que el cuerpo violentado no es su cuerpo, sino el cuerpo del victimario, hay un juego de propiedad que también se ve reflejado en la reparación. Así, la reparación de la víctima pasa por un recuperar la autoridad en su cuerpo y entenderlo ya no como un territorio de conquista. Esto lleva en sí mismo un cambio de los significados atribuidos en la experiencia de victimización. Recuperar el cuerpo como cuerpo soberano, es entender que nadie tiene el derecho de violentarlo ${ }^{21}$, ni tocarlo, ni mirarlo. Así también, hay una resignificación del cuerpo violentado al cuerpo de resistencia. Resistencia porque es demostrar la autonomía del cuerpo femenino no supeditado a ordenamientos masculinos, pero

21 En la atención psicosocial este aparece como problema central ya que muchas víctimas luego de la violación experimentan aversión o, por el contrario, adicción al sexo (Betancur, 2011). también porque éste se convierte en instrumento de narración de la violencia y con ello de demanda de justicia y verdad.

Ahora bien, el caso de las mujeres indígenas genera otra discusión mayor pues esta recuperación del cuerpo y su resignificación solo se logra en cuanto hay una recuperación del territorio y la discusión del cuerpo en las mujeres indígenas teje un puente con la economía política de la justicia transicional; es decir, entender que para rehabilitar la cotidianidad de la mujer indígena, desde su experiencia corporal, es necesario entender cómo la política económica del gobierno entra en tensión con las demandas de las mujeres. Arelis Guzmán por ejemplo, reconoce que:

Nosotras hemos dicho que la reparación debe ser justa, una reparación no a la repetición. Pero, a pesar de que venimos haciendo estas exigencias, se habla de reparación, pero a mí me parece que hablan es de desaparición. Borre todo. En un silencio total, y el resultado de todo eso es matemos a esa persona para olvidar. Hablan de restituir las tierras pero acallan a quienes piden una reparación colectiva, un cuidado por el territorio. Porque nosotros pensamos que la reparación debe ser colectiva, individual y espiritual. No la reparación que habla el gobierno de bueno vamos a comprar un pedazo de tierras para los indígenas, hay que reparar en educación digna, salud digna, vivienda digna. Vida digna en nuestros territorios, pero eso el Estado no sabe dárnoslo porque eso es algo que sólo nosotros desde nuestra cosmovisión podemos garantizar. Al Estado se le pide que nos deje actuar. (Comunicación personal, 10 de abril de 2013)

Para las mujeres indígenas la reparación tiene que ver con la lucha por un territorio seguro, de ahí que aunque muchas no narren y 


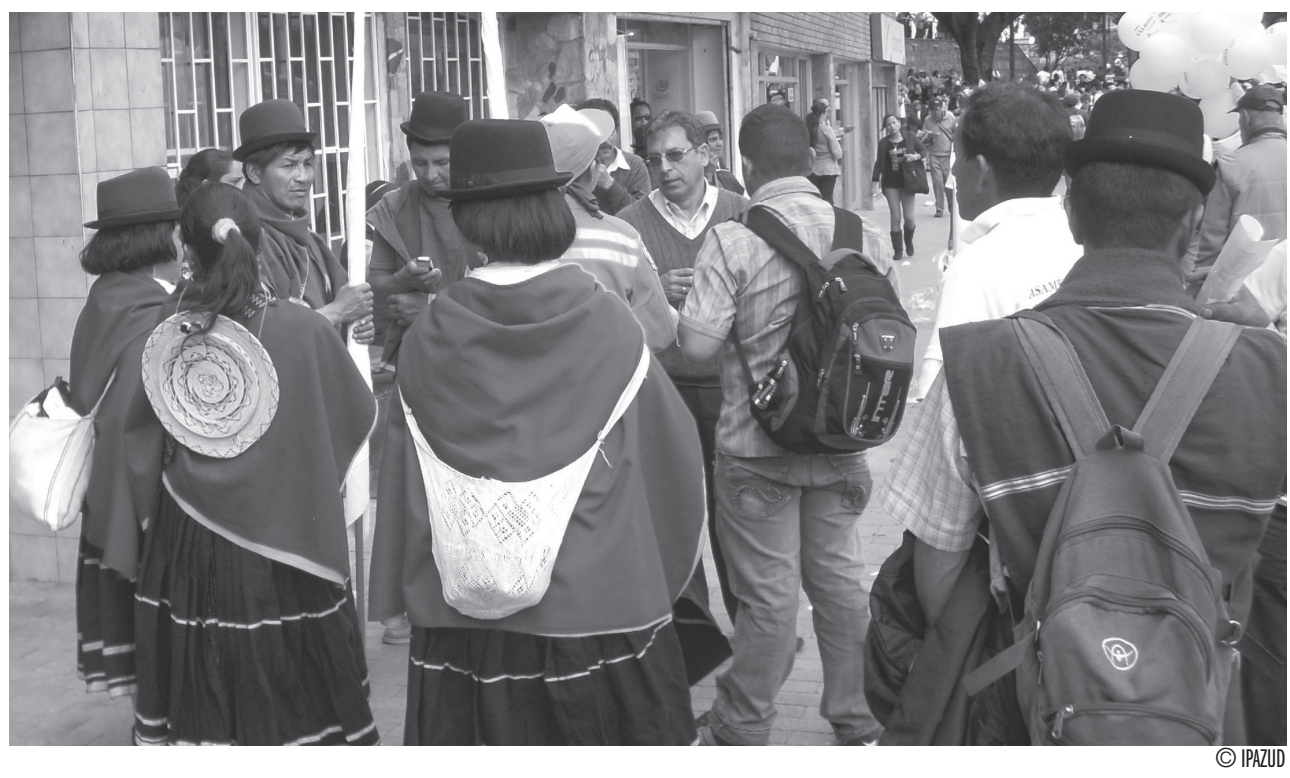

cuenten lo ocurrido como víctima de violencia sexual en el conflicto armado, sí llegan al espacio público por la defensa del territorio, porque saben que cuando ellas son violentadas el equilibrio de la comunidad se pierde. Violarlas a ellas, a su cuerpo, es violar la madre tierra, es violentar a la comunidad:

La única manera en que nos podemos reparar es utilizando nuestra medicina, pero eso no se puede hacer en estos momentos porque los territorios están invadidos. Otra cosa es bañarnos en el rio, entonces son todas cosas que están ligadas a tener un territorio libre de externos, que uno pueda transitar normal, donde se puedan hacer refrescamientos, hacer rituales de saneamiento y así. El hecho de violencia sexual va a quedar muy impune, porque es muy difícil llegar a todas las mujeres entonces no lo vamos a saber, porque no hay garantías para decirlo. Entonces eso será algo que quedará con mucha impunidad, a nosotras nos toca es luchar por nuestro territorio, así podremos hacer también algo por ellas. (A. Guzmán, comunicación personal, 10 de abril de 2013)

\section{La salida: Una justicia transicional desde abajo pero con el Gobierno}

Las esperanzas de una reparación integral parecen estar depositadas en las instituciones y el presupuesto nacional, o incluso en los recursos técnicos y financieros donados por la cooperación internacional. De allí que podamos hablar de una política transicional circunscrita al ámbito administrativo nacional, muy distante de las comunidades (Páez, 2011). Esta perspectiva vertical de los procesos de reparación subvaloran el potencial que tiene el que una víctima, en especial de violencia sexual, devenga en sujeto político para, por una parte, exigir sus derechos, y por otra, tramitar su dolor (Tabares, 2011). Una consecuencia clara de esto es que las medidas contempladas para reparar no están acordes a las necesidades reales de las víctimas. Para el caso indígena, lo primero es reconocer que manifestar públicamente el delito no es garantía de reparación, teniendo en cuenta el hecho de que el que una mujer declare públicamente el evento de violencia 
"no significa automáticamente que el reconocimiento público de su condición de víctima mediante la adopción de algunas medidas públicas y simbólicas de reparación conduzca a su redignificación" (Unifem, 2009, p.171), luego las medidas contempladas para repararlas no deben pasar como lo observa la ley, por una declaración pública, ni mucho menos por una indemnización administrativa o una atención psicosocial ligada al diagnóstico clínico más que a la comprensión de la situación sociocultural de la mujer indígena. En vez de ello, exige pensar en un replanteamiento de la política económica basada en un modelo de extracción. En tal caso, la locomotora minera del gobierno de Juan Manuel Santos entra en tensión con su agenda de paz en lo relacionado con la reparación a las víctimas.

Bajo la argumentación presentada, identificar las potencialidades que hay sobre el escenario colombiano para reparar integralmente a las mujeres depende del reconocimiento que la reparación no puede ser entendida de una forma estrictamente vertical. En contraste, es la participación de las víctimas, la sociedad civil, comunidades y diversos organismos internacionales lo que posibilitaría una reparación integral. Esto se da por dos motivos: primero, son muchas las tareas y deudas pendientes con las víctimas, y son limitadas tanto la capacidad institucional como los recursos para garantizar cada uno de los componentes de la reparación -adecuada, diferenciada, transformadora y efectiva- , en sus diversas formas -individual, colectiva, material, moral, simbólica y como lo han definido las mujeres indígenas "espiritual"- y con las medidas planteadas -restitución, indemnización, rehabilitación, satisfacción y garantías de no repetición-. Darles participación en el proceso a las víctimas no solo es aceptar que toda la sociedad civil también tiene una responsabilidad con éstas, sino también que ser víctima no es sinónimo de ser paciente y "beneficiario":

Entonces la reparación debe ser algo que garantice, proteja y atienda en los momentos necesarios, que no sea algo como los programas asistencialistas, que si eres victima ha bueno te vamos a dar una casita, un pedacito de tierra, y a garantizarte que no te falte nada, cuándo será que los verdaderos actores armados puedan pedir disculpas a las víctimas. (A. Guzmán, comunicación personal, 10 de abril de 2013)

Segundo, es imposible pensar una reparación adecuada, eficaz y diferencial, sin escuchar a las víctimas. Como se había sostenido, el enfoque diferencial permite ser sensible a las diferentes formas en que se ha dado la experiencia de la victimización. Entender estas formas pasa por un proceso de escuchar a las víctimas. Solo ellas pueden determinar qué es lo justo para su reparación. No hacerlo incurriría en una reparación que no tenga como principio la satisfacción de quien es reparada.

Ahora bien, en contextos donde hay ausencia de mecanismos viables de justicia transicional, es usual que se desate una "fuerza creativa" para la transición desde abajo (McEvoy \& McGregor 2008), en especial, cuando el sistema nacional de justicia aparece como incapaz de resolver todas las violaciones a los derechos humanos, indispensable en cualquier proceso de transición. La observación internacional demuestra que las estrategias de transición forjadas en el ámbito local, o «desde abajo» pueden resultar más eficaces, eficientes, sostenibles y legítimas que aquellas adoptadas por los centros clásicos de poder estatal $^{22}$. La metodología incluyente de este

22 Uno de los autores que ha trabajado este enfoque desde abajo de la justicia transicional es Harry Mika; para él, existe un gran consenso en que el cambio debe provenir desde el gobierno o desde 
enfoque (McEvoy \& McGregor, 2008), permite la participación directamente con las víctimas, las comunidades, las iglesias, las organizaciones de la sociedad civil y, en general, los actores políticos no estatales. Así pues, facilita la adopción de esquemas diferenciales para la garantía de los derechos a la verdad, la justicia y la reparación, coherentes con las características socioculturales de cada población, y aporta en el empoderamiento de las comunidades al tratarlas como las protagonistas de la reconciliación y la reparación. Otras ventajas de este enfoque son su tendencia a favorecer la movilización y reconstrucción del tejido social ${ }^{23}$ y en últimas, la legitimidad democrática de la política de transición.

De este modo, la tendencia a crear y ejecutar los mecanismos de la justicia transicional de manera centralizada y universalista, al margen de las voces de las víctimas, aleja las políticas de las vidas cotidianas de éstas y pueden entonces tener efectos parciales en la democratización de los países. Para evitar que estas respuestas parciales resulten inadecuadas, es importante poner a dialogar la aproximación desde el Estado y el derecho, con la aproximación desde las víctimas (Uprimny \& Guzmán, 2010). El apostarle al Estado como agente central de la reparación puede ser riesgoso si no se tienen claras las limitaciones del mismo, sobre todo cuando lo que se busca es una reparación integral, que amerita la ejecución de procesos simultáneos como la reparación, la restitución, indemnización, rehabilitación, satisfacción y garantías de no repetición.

las organizaciones internacionales las cuales se roban siempre toda la atención (2009), pero la comunidad está llamada a jugar un papel importante en esta idea de justicia transicional, precisamente porque el Gobierno tiene un rol limitado. Para examinar esto a partir de estudios de caso internacionales véase: Mika, 2006; Mika. Et al, 2004. 23 Ver Kisten McConnachie \& John Morison. Constitution-making, transition and the reconstruction of society. En McEvoy y Mc Gregor, 2008.
Para el caso de las mujeres indígenas, como ellas mismas lo manifiestan, de la reparación solo pueden hacerse a cargo ellas a través de sus pagamentos y medicinas tradicionales, que exigen de parte del Estado el respeto a sus territorios ancestrales. De modo que, así como ellas son las protagonistas de este proceso, necesitan de la coherencia del Estado en querer resarcirlas y que sus programas económicos no afecten los planes dispuestos a este respecto. En tal caso, la justicia desde abajo es entendida en términos de reconocer la lucha de las mujeres indígenas por el territorio y de ellas como las únicas capaces de rehabilitar su cotidianidad.

\section{Consideraciones finales: costos políticos de una reparación pensada como indemnización}

A pesar de su creciente entramado institucional, el balance global de las reparaciones es, para decir lo menos, modesto, si no desalentador (De Greiff, 2006b). No sólo es común que no se reparen los daños sino que quienes terminen asumiendo la principal responsabilidad en la generación y provisión de recursos sean los Estados, desviando recursos de otras tareas de inversión social (Segovia, 2006). Por su parte, el tema del impacto fiscal y la inversión del Estado en materia de reparaciones sigue siendo el fantasma que ronda la ejecución de la Ley; el Estado y la sociedad deben hacer los esfuerzos necesarios para que las disposiciones establecidas en esta se hagan realidad. El efecto simbólico de su aprobación y el compromiso del Gobierno se tornarán negativos si no se traducen en medidas concretas y específicas que vayan más allá de la entrega disfrazada de unos beneficios sociales o unos reconocimientos vacíos (Uprimny, 13 de agosto de 2011). 
Los programas de reparación que operan en ausencia de otras medidas de justicia, invitan a la interpretación de que los beneficios que distribuyen son la moneda con la que el Estado intenta comprar el silencio o la aquiescencia de las víctimas y sus familias, haciendo de los beneficios "dinero manchado de sangre". De ahí que sea importante garantizar que los esfuerzos de reparación sean coherentes con otras iniciativas de justicia que comprenden enjuiciamientos, confesión de la verdad y reforma institucional. (De Greiff, 2006a, p.240)

A esto se agrega que los mecanismos transicionales suelen poner sobre la base una concepción pasiva de las víctimas, éstas aquí son despojadas de toda acción orientada a la superación de las secuelas dejadas por la violencia y no se les reconoce su capacidad de resiliencia ${ }^{24}$ en contextos altamente violentos.

Pero también puede suceder que los esfuerzos centralizados en una reparación como indemnización ahoguen las iniciativas de las víctimas de exigir verdad, justicia y reparación. Ello teniendo en cuenta que en la puesta en práctica después de instaurada la ley 1448 , se ha concentrado en la asistencia y no en los contenidos simbólicos. Reparar por medio de la asistencia las vuelve dependientes de élites (profesionales y políticas) (Mika, 2009). De modo que, en su condición de vulnerabilidad, muchas de las mujeres víctimas de violencia sexual prefieren recibir mensual-

24 La resiliencia según Cyrulnik (2006) es la capacidad que tiene un ser humano (niño, adolescente, adulto) a pesar de sus dificultades personales (físicas, mentales y psíquicas), para intuir y crear, en circunstancias desfavorables o en un entorno destructor, respuestas que le hacen posible no dejarse atrapar por las circunstancias y dificultades personales ni por las condiciones del entorno sino por el contrario, proponer y realizar comportamientos que le permiten una vida con menos sufrimiento y encontrar un lugar en su medio ambiente, lo cual le permite desarrollar sus capacidades y anhelos. Para más trabajos sobre este concepto véase Manciaux (2003) y mente ayudas estatales, que exigirle la investigación y juzgamiento del crimen de la que fue víctima, por ejemplo. Esto deriva en que la víctima se rescata como víctima carente de ayuda estatal y no como ciudadana, lo cual contradice parte de lo que la ley reconoce como reparación integral. En tal caso, deben tenerse en cuenta los usos diferenciados de la memoria, pues si bien hay muchas que quieren callar y borrar lo sucedido para poder rehacer sus vidas lejos del recuerdo de la victimización, muchas de ellas también buscan ser testimonio, no solamente con el relato de la experiencia personal, pero sí con la participación en las discusiones sobre formas de reparación o con manifestaciones de memoria. Hacer esta consideración resulta cuidadoso con imponerle un papel de responsabilidad política de las víctimas para con sus pares, pero también reconoce que muchas de ellas quieren hablar aún cuando no haya garantías para ello o aún cuando no lo hagan en nombre de la violencia sexual sino del territorio como en el caso indígena.

Pablo de Greiff (2006a) sugiere que una cosa es conceder reparaciones dentro del marco de un sistema jurídico básicamente operativo en casos relativamente aislados de abuso, y otra, conceder reparaciones dentro de un sistema que necesita ser reconstruido en algunos aspectos fundamentales, o peor aún, que debe construir por primera vez, precisamente porque condonó o hizo posibles abusos sistemáticos de derechos humanos. En casos de abusos masivos, el interés por la justicia exige más que el intento de resarcir los daños particulares sufridos por individuos particulares. Cualquiera que sea el criterio de justicia que se defienda, deberá también tener en la mira las condiciones previas para reconstruir el Estado de derecho, objetivo que conlleva una dimensión pública o colectiva. 


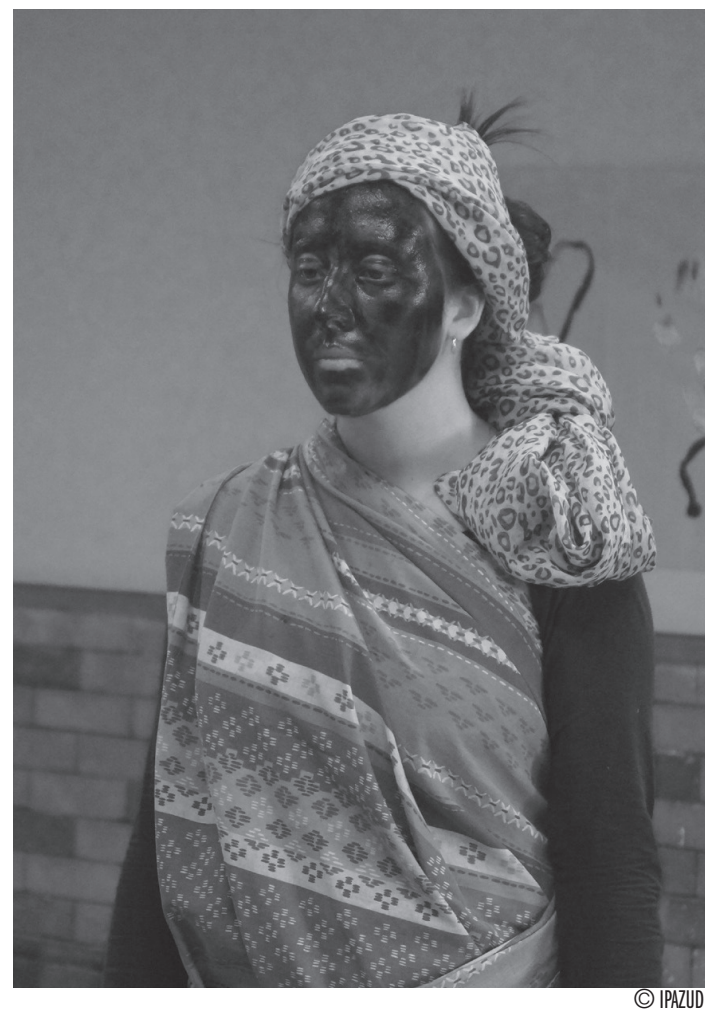

Ahora bien, dado que las reparaciones contribuyen a alcanzar la justicia, ello porque es la violación de derechos iguales la que desencadena el suministro de medidas compensatorias (por ejemplo el derivado de los DESC en donde la mujer tiene igualdad de derechos con el hombre, y por tanto, no podrá ser sometida a ninguna clase de discriminación), al momento de necesitarse una compensación, ésta se da porque se requiere la igualdad de los ciudadanos, la justicia.

La compensación debida a las víctimas, en justicia, se deriva directamente de la violación misma de los derechos comunes a la ciudadanía, y no de la posición particular de cada individuo antes de la violación. De modo que, la obligación fundamental de la reparación no es la de regresar a la persona a su status quo antes, sino la de ofrecerle una indicación confiable del hecho de que el régimen subsiguiente se ha comprometido a respetar la igual- dad de derechos de todos los ciudadanos. Lo que en palabras de De Greiff, implica claramente tanto un elemento retrospectivo como un elemento prospectivo. En el primero, los beneficios deberán ser suficientes en magnitud como para constituir un reconocimiento adecuado de la gravedad percibida de la violación a los derechos iguales de los ciudadanos. En el segundo caso, la magnitud de los beneficios debe ser suficiente para demostrar las intenciones del gobierno de comportarse de manera diferente en el futuro.

Una reparación que piense en los ciudadanos como iguales, en el diseño y la implementación, exige la participación de las víctimas. Es posible que una imposición paternalista de beneficios, que no consulte a quienes los reciben o que no cuente con su participación, termine por debilitar el objetivo de reafirmar a las víctimas ante los demás o ante sí mismas como ciudadanas de derechos iguales. De ahí que se debe dar a la sociedad civil un papel importante en el diseño e implementación de los programas de reparación, porque además puede así recobrar la confianza de los ciudadanos en las instituciones estatales. Con ello se sugiere que no basta con que las medidas jurídicas y administrativas sean complementarias como lo sugiere Lozano (2009), sino que también lo sean los procesos que se llevan a cabo desde las instituciones y desde las comunidades $u$ organizaciones de víctimas. Es necesario dejar de pensar la reparación como un proceso vertical donde las víctimas esperan ser reparadas, a uno pensado en el diálogo entre la aproximación desde el Estado y el derecho, con la aproximación desde las víctimas.

Ahora bien, es posible establecer que la pregunta por el cuerpo dentro de las formas en que las víctimas de violencia sexual interpretan la reparación para ellas, permite en- 
tenderlas como sujetos políticos, pues en su vida diaria llevan a cabo prácticas orientadas a sobrellevar los efectos de la experiencia de victimización, que en el caso estudiado, implica el re-conocimiento de sí misma y la asimilación y apropiación de un cuerpo destrozado material, espiritual y psicológicamente a causa de la violencia. Estas violencias inscritas en sus cuerpos y las formas en que ellas las tramitan, muestran que la posibilidad de reparar integralmente excede la capacidad del Estado, haciendo aparecer otros agentes en la reparación; como por ejemplo ellas mismas, las organizaciones de víctimas que abren espacios de reunión, y las comunidades que para el caso indígena son garante de "recuperar el cuerpo". Las iniciativas de las víctimas para repararse por eso parecen tener, desde la lectura que hace Tabares (2011), un gran potencial reparador porque las sitúa como agentes, y porque con ellas tramitan el sufrimiento producto de la victimización, así como resignifican sus cuerpos marcados por la violencia. La forma de rehabilitar la cotidianidad pasa por un re-conocimiento del cuerpo mismo como cuerpo que ya no evoca violencia sino resistencia.

Así mismo, la pregunta por el cuerpo para el caso indígena pone de manifiesto que pensar en una economía política de la justicia transicional es importante a la hora de evaluar las medidas de reparación que son adoptadas. Es decir, si la aplicación de políticas de transición atiende a las particularidades de contextos locales, o por el contrario, se expresan en recetas que al fin no dan cuenta de las necesidades reales de las víctimas. Es en la medida en que las reparaciones busquen rehabilitar la cotidianidad que pueden derivar en un aporte para la paz; de lo contrario, las medidas de reparación quedarán consignadas en una lista de logros de los gobiernos que poco o nada valdrán realmente para las comunidades.

\section{Referencias bibliográficas}

- Amnistía Internacional. (2004). Colombia: Cuerpos marcados, crímenes silenciados. Violencia sexual contra las mujeres en el marco del conflicto armado. Madrid, España: Amnistía Internacional. Recuperado de http://bit.ly/1kegYs2

- Amnistía Internacional. (2011). "Eso es lo que nosotras exigimos que se haga justicia" Impunidad por actos de violencia sexual cometidos contra mujeres en el conflicto armado colombiano. Madrid, España: Amnistía Internacional. Recuperado de http://bit.ly/1ojjaOP

- Betancur, N. (2011). Posibilidades, obstáculos y recomendaciones para la exigencia de las mujeres del derecho a la verdad, la justicia y la reparación desde el ámbito psicosocial. En Montealegre, D. et al, Verdad Justicia y Reparación: una deuda pendiente con las mujeres y víctimas de las violencias (pp.59-79). Bogotá, Colombia: G2 editores.

- Butler, J. (2010). Marcos de Guerra. Las vidas Iloradas. Madrid, España: Paidós.

- Cadavid, L. (2006). El ser-corporal-en-el-mundo como punto de partida en la fenomenología de la existencia corpórea. Pensamiento Educativo, 38, 46-61. Recuperado de http://bit.ly/1mKlglc

- Chinkin, C. (1994). Rape and Sexual Abuse of Women in International Law. European Journal of International Law, 5(1), 326 - 341.

- CINEP. (2012). Informe especial: Conflicto Armado en Colombia durante 2011. Bogotá: Cinep. Recuperado de http://bit.ly/1nYpxlp

- Corte Constitucional. (2008). Auto Nº92 de 2008. Bogotá.

- Cyrulnik, B. (2001). La maravilla del dolor: el sentido de la resiliencia. Barcelona, España: Granica.

- Cyrulnik, B, et al. (2006). La resiliencia: desvictimizar la víctima. Cali: Feriva.

- Das, Veena. (1996). Language and Body: Transactions in the construction of Pain. Social Suffering, 125 (1), 67-91.

- De Greiff, P. (2006a). Enfrentar el pasado: reparaciones por abusos graves a los derechos humanos. En de Gamboa, C (Ed.), Justicia transicional: Teoría y Praxis (pp.204-241). Bogotá, Colombia: Universidad del Rosario.

- De Greiff, P. (2006b). Justice and reparations. En De Greiff, P (Ed.), The Handbook of reparations (pp.451 - 477). Oxford: Oxford University Press

- Fondo de Desarrollo de las Naciones Unidas para Mujer UNIFEM. (2009). ¿ Justicia desigual? Género y derechos de las víctimas en Colombia. Bogotá, Colombia: Pro-offset editorial S.A.

- Horenstein Battán, A. (2004). Hacia una fenomenología de la corporeidad. Merleau Ponty y el problema del dualismo. España: Editorial Universitas.

- Ibáñez, A. M \& Moya A. (2010). Vulnerability of Victims of Civil Conflicts: Empirical Evidence for the Displaced Population in Colombia. World Development, 38(4), $647-663$.

- Kalmanovitz, P. (2010). Justicia correctiva vs. Justicia social en casos de conflicto armado. Estudios Socio-Jurídicos, 12, (2), 59-85.

- Londoño, L. \& Nieto, Y. (2006). Mujeres no contadas. Proceso de desmovilización y retorno a la vida civil de mujeres excombatientes en Colombia. Medellín, Colombia: La Carreta Editores. 
- López, C. (2010). Hermenéutica del cuerpo doliente-dolido desde la fenomenología del sentir. Investigaciones Fenomenológicas, 2, 89-123.

- Lozano, C. (2009). Entre la distribución y el reconocimiento: percepciones de las víctimas sobre inversión social focalizada a causa de la masacre de Bojayá. En Gómez, C., Sánchez, N., \& Uprimny, R. (Eds.), Reparar en Colombia: los dilemas en contextos de conflicto, pobreza y exclusión (pp. 31-70). Bogotá, Colombia: ICJT y DeJusticia.

- Manciaux, M. (2003). La resiliencia: resistir y rehacerse. Madrid, España: Gedisa.

- Mani, R. (2006). Reparations as a Component of Transitional Justice: Pursuing "Reparative Justice in the Aftermath of Violent Conflict. En De Feyter, $\mathrm{K}$ et al. (Eds.), Out of the Ashes: Reparation for Victims of Gross and Systematic Human Rights Violations (pp.53-82). Intersentia, Antwerpen and Oxford.

- McEvoy, K., \& McGregor, L. (2008). Transitional justice from Below, Grassroots Activism and the struggle for change. North America: Oxford and Portland, Oregon.

- Memoria Histórica. (2010). La Masacre de Bahia Portete: Mujeres wayuu en la mira. Recuperado de http://bit.ly/1rPVXUe

- Memoria Histórica. (2011). Mujeres y guerra. Víctimas y resistentes en el Caribe. Bogotá, Colombia: Taurus, Fundación Semana, CNRR, GMH.

- Memoria Histórica. (2012). Síntesis de los informes Mujeres y Guerra. Victimas y resistentes en el Caribe colombiano y Mujeres que hacen historia. Tierra, cuerpo y política en el Caribe Colombiano. Revista de estudios sociales, (42), 153 - 156.

- Mesa Nacional de Seguimiento al Auto 092. (Marzo de 2011). Balance de la implementación del programa de promoción de la participación de la mujer desplazada y de prevención de la violencia sociopolítica contra las mujeres líderes de población desplazada; en el marco de las órdenes proferidas por la honorable corte constitucional en el auto 092 de 2008 y siguientes.

- Mesa de trabajo Mujer y Conflicto Armado. (2009). IX informe sobre violencia sociopolítica contra mujeres, jóvenes y niñas en Colombia. Bogotá: Ediciones Antropos.

- Mika, H. (2006). Community based Restorative Justice in Northern Ireland. Belfast: Queen's University.

- Mika, H. (2009). Sobre el concepto de justicia transicional desde abajo. Entrevista con el profesor Harry Mika. En Gómez, C., Sánchez, N., y Uprimny, R. (Eds.), Reparar en Colombia: los dilemas en contextos de conflicto, pobreza y exclusión (pp.227-246). Bogotá, Colombia: Opciones Gráficas Editores, Ltda.

- Mika, H., et al. (2004). Listening to Victims. A Critique of Restorative Justice Policy and Practice in the United States. Federal Probation, a Journal of correctional philosophy and practice, 68 (1). Recuperado de http://1.usa.gov/1qCUQdj

- Nancy, J. (2008). Corpus. New York: Fordham University Press.

- Organización Nacional Indígena de Colombia. ONIC. (2012). Mujeres Indígenas, víctimas invisibles del conflicto armado en Colombia. La violencia sexual, una estrategia de guerra. Bogotá, Colombia. Recuperado de: http://bit.ly/1t4INWb

- Orozco, I. (2009). Justicia Transicional en tiempos del deber de la memoria. Bogotá, Colombia: Temis.

- Ortega, F. (2008). Rehabilitar la cotidianidad. En Ortega, F (Ed), Veena Das: Sujetos del dolor, agentes de dignidad (pp.15 - 69). Bogotá, Colombia: Universidad Nacional de Colombia.

- Oxfam Internacional. (2009). La violencia sexual en Colombia. Un arma de guerra. Recuperado de http://bit.ly/1nF6KBx

- Oxfam Internacional. (2010). Violencia sexual en contra de las mujeres en el contexto del conflicto armado colombiano. Primera encuesta de prevalencia Colombia 2001-2009. Recuperado de http://bit.ly/1nmmMil

- Páez, M. (2011). La justicia transicional desde abajo. Revista Zero, 26, 36 - 42. Recuperado de http://bit.ly/1rEqTcv

- Rawls, J. (1995). Liberalismo Político. México: Fondo de cultura económica.

- Rettberg, A. (2008). Reparación en Colombia ¿qué quieren las víctimas? Bogotá: Panamericana.

- Rincón, T. (2010). Verdad, Justicia y Reparación. Bogotá, Colombia: Universidad del Rosario.

- Salcedo, D. (2007). Las mujeres en el conflicto armado colombiano: violencias, resistencia y reparación. Mesa de trabajo mujer y conflicto armado.

- Segato, R. (2003). Las estructuras elementales de la violencia: contrato y status en la etiología de la violencia. Brasilia, D.F: Universida de Brasília.

- Segato, R. (2009). La guerra en el cuerpo. Entrevista realizada por Roxana Sandá. Recuperado de http://bit.ly/1nF8F8V

- Segovia, A. (2006). Financing Reparations Programs: Reflections from International Experience. En De Greiff (Ed.), The Handbook of reparations (pp.650-675). Oxford: Oxford University Press.

- Serres, M. (2011). Variaciones Sobre el Cuerpo. Buenos Aires: Fondo de Cultura Económica.

- Tabares, O. (2011). Reflexiones en torno al devenir sujeto político de las víctimas del conflicto armado. Estudios Políticos, (38), $13-37$.

- Uprimny, R. (2009). Reparaciones transformadoras de violaciones masivas de derechos humanos: entre justicia distributiva y justicia correctiva. Lección inaugural presentada como profesor visitante en la Universidad de Utrecht en la Cátedra UNESCO de Educación para la Paz, los Derechos Humanos y la Democracia.

- Uprimny, R. (13 de agosto de 2011). Ley de Víctimas: avances, limitaciones y retos. UN Periódico. Recuperado de http://bit.ly/1nCE2PZ

- Uprimny, R. y Guzmán, D. (2010). En búsqueda de un concepto transformador y participativo para las reparaciones en contextos transicionales. Revista Colombiana de derecho internacional, (17), 231-286.

- Uprimny, R. y Saffon, M. P. (2007). Usos y abusos de la justicia transicional en Colombia. Recuperado de http://bit.ly/1rFzknT

- Uprimny, R. y Saffon, M P. (2009). Reparaciones transformadoras, justicia distributiva y profundización democrática. En Gómez, C., Sánchez, N., y Uprimny, R. (Eds.), Reparar en Colombia: Ios dilemas en contextos de conflicto, pobreza y exclusión (pp.31-70). Bogotá, Colombia: Opciones Gráficas Editores, Ltda.

- Wills, M. E. (2011). La memoria histórica desde la perspectiva de género. Conceptos y Herramientas. Bogotá, Colombia: CNRR, Grupo de Memoria Histórica. 